\title{
The Application Analysis of Computer Technology in Dance Teaching
}

\author{
Rensisi \\ Linyi University, Yishui, Shandong, 276400
}

\section{Keywords: Computer technology; Dance; Teaching}

\begin{abstract}
With the continuous development of computer technology, its application increases gradually in various disciplines' teaching. The application of computer technology in dance teaching also has certain feasibility. On the one hand, computer audio technology provides corresponding music for dance teaching, and on the other hand, computer network can improve the defects of traditional teaching mode. This paper focuses on analyzing the effective application of computer technology in dance teaching.

In the process of modern education technology development in our country, the earliest was audio-visual education. Since film and slide were introduced into China, some colleges and universities also gradually used film and slide in education teaching, which was the symbolic that education entered the age of modern education technology in our country. With the continuous development of computer technology, its application increasingly spread in education teaching. In dance teaching, the application of computer technology not only can improve the deficiency of traditional teaching mode, at the same time it can also provide dance teaching effectiveness.
\end{abstract}

\section{The application value of computer technology in dance teaching}

\section{Make up for the deficiency of traditional teaching.}

The application of computer network technology in dance teaching can not only upload traditional teaching courseware and teaching plan to computer network and facilitate students' learning, at the same time it also can increase the effective application of other resources in teaching. The development of computer network further expands teaching resources and realizes effective integration of social resources and curriculum resources on the network platform. It not only helps students' learning resources outside of the classroom, also further expands students' vision and effectively complements the defects of traditional teaching mode to realize the integrity of teaching system.

\section{Enrich teaching methods.}

Relatively speaking, traditional teaching method is unitary, and the application of computer network can further enrich classroom teaching mode. Teaching process, with the aid of computer network, can not only provide general text, at the same time can also provide visual images, live video, multimedia presentations and different music and so on. If necessary, interactive games can be applied. The application of computer network has important application value in the process of dance teaching.

\section{Breakthrough time and space constraints.}

In traditional teaching mode, space constraints result in a certain people limit in teaching process. In computer network teaching, usually there are no restrictions. No matter how many students are there in the classroom, they can use network platform to let every student get the corresponding teaching resources, and can also formulate the corresponding teaching methods and teaching content based on their own needs, such can not only reduce teachers' burden, but also can significantly improve the quality of classroom teaching. And computer network technology improves time limitation problem in traditional teaching mode. Network teaching material is more abundant, and in the process of learning it can also instruct dance extracurricular teaching. Thus, this becomes an important extension of classroom teaching mode, enriching the content of students' learning and further increase students' learning time. 


\section{The application strategy of computer technology in dance teaching}

\section{Computer audio processing software application in teaching.}

Dance teaching process needs to apply a lot of music. Different music teaching is also needed in different stages, and the music can be tailored. The commonly used computer audio processing software in dance teaching includes SONAR, MP3, etc. In accordance with dance characteristics and basic requirements, audio-visual material conversion extraction and editing, etc., thus it can produce music interacting dance teaching or performance. The following process is needed to be processed in its application:

(1) Dance teaching music collection and extraction

In the process of dance music application, usually the format is not necessarily audio formats. Some just appear in video. AVI MPEG WMV RM to MP3 Converter can extract audio files in video files and its can be successfully converted to MP3 and WAV format. The software can support a variety of video and audio formats such as AVI, MOV, WMVASF and so on. We discuss ballet little kick music extraction. The software used AVI MPEG WMV RM to MP3 Converter. First open the software, select video file "little kick music" needed to be processed in the computer; Secondly based on dance teaching needs, determine the little kick music from 00:00:51-00:02:18 stage, and directly determine the start time and end time; (3) click on the transform icon, determine clip file storage location, and finally click the software to began to store the MP3 file. With the above operations, successfully extract small kick audio, and in the application, the software has a friendly interface, the advantages of convenient operation, and can extract and convert the whole or fragments to MP3 files according to customers' actual needs. However, it cannot mix different audio files for editing.

(2) The application of dance teaching music synthesis software SINAR

In dance teaching music selection process, some of the music is not ready and must be edited synthetically. This time SINAR software can be applied. This software can not only play monophony music and polyphony, also it can apply a variety of phonies. The user need to have a certain musical knowledge, can read music notation, understand mode key signatures, and can carried out dance teaching music synthesis edition. Here we take Chinese dance foundation training music, "Mop the Floor", as an example, to analyze SINAR software applications. 1, open the software; 2, execute commands in menu "Options/MIDI Devices", choose MIDI input and output equipment for the pop-up window; 3, click to build two MIDI audio files, and set the name to "Mop the Floor". Focus the same nature tracks using the mouse for management; 4, shoot, clef, and set a key signature. Click on Transport (Large) toolbar. Calls the tempo and the window for adjusting, and set the tempo to $2 / 4$, and key signature C; 5 , set the speed of the music to 80 ; 6 , set sound channel attributes. Distribute input port settings such as music name, channel number, timbre, and output parameters in the process. Click on the track, we can see the relevant parameter settings window, and make related parameter settings. The track name is set to "Strongl", and in the process of application, select article 3 MIDI channel. The tone is set to "Acoustic Grand Poin", and others can choose all the default settings; 7, record music melody, which can be divided into: the first kind: mouse input. This approach is simple and well made in application process. The second is MIDI keyboard input, whose speed is faster, but must have corresponding piano playing skills; 8, realize melody processing. Use menu command "Process/Quantize", set effect in dialog box to improve the artistic quality of music melody, and music melody errors must be controlled within a certain range; 9, export audio files. It successfully synthesizes the music "Mop the Floor" by software SINAR, which can be applied in dancing teaching.

\section{Multimedia teaching implements dance computer network.}

Dance teaching content is under the guidance of "National Ordinary Higher School Physical Education Curriculum Teaching Instruction Summary" promulgated by the Ministry of Education. Usually in the process of teaching, teaching material is College Sports and Health Education. Then based on this curriculum guide, you can choose dance classes' excellent teaching material and formulate reasonable teaching methods. In the study of teaching methods, personalized and 
diversified characteristics are needed to be satisfied. Active advocating realizes the good interaction between teachers and students as well as the perspectives of communication, which can significantly improve student participation in the classroom, and effectively stimulate students' creativity. In the process of teaching, we also need to strengthen students' learning methods and practice guidance, and cultivate students' ability of self-study and practice ability. The main role of courseware in the process of classroom teaching is auxiliary teaching, and its quality has a direct impact on classroom teaching effect, so in teaching process, we must optimize courseware teaching design. Pay attention to the artistic quality of courseware design, teaching model and ease of use. So, in multimedia courseware design, we need to pay attention to achieve the above requirements.

\section{Computer network teaching and traditional teaching.}

In dance teaching process, we must realize the effective combination of theory and practice. If there is no actual operation practice in teaching process, students can't effectively master the art of dance. So, in the teaching of computer network, we cannot purely apply network, but we must realize the effective combination of traditional teaching and network teaching, pay attention to complement each other to achieve both supplement of each other. Not only give full play to teachers' leading role, but reflect the students' main body status in the process of classroom teaching. Implement effective teaching, and achieve effective learning of students. Give full play to teachers' and students' enthusiasm and initiative. So, in teaching process, we must not put network teaching on the opposite of traditional teaching. In fact, network teaching is the supplement of traditional teaching, and traditional teaching is the foundation of network teaching. Achieve a good combination of network teaching and traditional teaching. It not only can expand traditional teaching capacity, but further enhance teachers' guidance and mistakes correct. It can significantly improve the problem in traditional teaching mode, and traditional teaching can make monitoring and incentive impact on network teaching. Only on this basis can we effectively give full play to the application value of computer network teaching in dance teaching.

\section{Conclusion}

To sum up, we can clearly see that computer technology has important application value in dance teaching. Also in dance teaching computer technology application, first further strengthen information quality education in dance classroom, improve teachers' application ability of computer and multimedia courseware; Second school needs to increase capital investment to improve school teaching facilities, give the corresponding reward for teachers' application of computer in dance teaching courseware and teaching, etc. to improve the effective utility ratio of computer in dance teaching. At the same time, give full play to computer teaching's application value. In dance teaching, both music and dance are sister art, and the relationship between the two is green leaves and red flowers and cannot be short of one the other. The application of computer audio processing software in dance teaching can effectively achieve the good combination of music and dancing and improve music dance teaching application value. And in dance teaching process, pay attention to realize multimedia teaching practice, and pay attention that traditional teaching and network teaching both supplement each other. Only in this way can we give full play to the advantages of application of both to lay a good foundation of improving the quality of dance classes teaching.

\section{Reference}

[1] Jia Xiufang. Reasonable application of multimedia technology in dance teaching [J]. Cultural and Educational Materials, 2010, (19) : 173-174.

[2] Zha Yan. The application research of digital media technology in sports dance teaching [D]. Dalian University of Technology, 2014.

[3] Li Qianyun. Modern education technology analysis in dance teaching [J]. Journal of Art, 2011, (11) : 120-121. 
[4] Zhang Jie. Introduction to dance teaching combined with information technology [J]. Computer CD Software and Applications, 2015, (2) : 229-230.

[5] Dawei Liu. Computer information technology application in dance teaching [J]. Journal of Contemporary Education Practice and Teaching Research (electronic edition), 2016, (9) : 14-14.

[6] Zeng Zheng. Dance teaching based on music editor technology [J]. Journal of Popular Literature and Art, 2014, (15) : 240.

[7] Wang Luchen, Han Li, Wang Yulong. Digital dance teaching method research based on the motion capture technology [J]. Journal of Information Technology Education in China, 2016, (6) : 71-74.

[8] Zhu Ping. Network course application research in ordinary university sports dance teaching [J]. Science and Technology in Western China, 2011, 10 (30) : 76-77,65. 